\title{
VIEWPOINT
}

\section{The spatial impact of migration}

\author{
Cristina Cassandra Murphy \\ XCOOP, The Netherlands \\ cmurphy@xcoop.org
}

\begin{abstract}
Migration across national borders has an increasing impact on cities. Traditionally, cities have been the locus of cultural, religious, social, and economic exchange, which is a fundamental characteristic of a thriving network. However, the urban division of inside (local) and outside (global) is still problematic even though we are moving toward true heterogeneous metropolis. This division results in "inequity" within society, urbanism, architecture and their related fields. A key to improving this societal issue is to understand, rethink, and challenge the division between "inside" and "outside". To do so, we (XCOOP Rotterdam and the Centros Urbanos Javeriana, Bogotà) have proposed a "hypothetical sustainable multi-cultural city" that aims at integration of immigrants through the creation of an "in-between" space that encourages integration among immigrants and receiving communities. The success of this space will depend on the degree of inclusiveness: local and global residents will need to lead the transformation and any new intervention ought to satisfy communal interests. We have been studying this designbased proposal for a while and since May 2017, we have been working with students and communities (interactive workshops), experts in the field (international conferences), and universities (on-site performances and exhibition) in the following four cities: Bogotà, a city that is economically unbalanced and lacks accessibility to essential goods; Tucson, a city that faces issues of homelessness and segregation; Baltimore, an urban setting that confronts geographical segregation and inequity; Rotterdam, a metropolis focusing on the growth and development of global companies rather than its local residents.

The results of these efforts include the following conclusions:

- the "in-between" spaces foster opportunities for positive encounters among different groups in public spaces;

- the "in-between" spaces rely on equal accesses to public services and goods;

- successful implementation of "in-between" spaces requires new typologies and improved methods of participatory design.
\end{abstract}

Keywords: migration, globalization, inequity, inclusiveness, design

\section{To cite this article:}

Murphy, C. C. (20I8). The spatial impact of migration. The Journal of Public Space, 3(3), I59-170, DOI 10.3289I/jps.v3i3.1139

This article has been reviewed and accepted for publication in The Journal of Public Space. 


\section{Introduction: "designing for immigration"}

Immigration is, today, a common condition in urban conditions around the world. What's more, we are increasingly becoming an urban world, across the spectrum of developed and developing economies.' Cities have long been the locus of cultural, religious, social, and economic exchange, which is a fundamental characteristic of a thriving urban economy. Yet designing adequately for immigrants in Western cities is challenging due to the lack of comprehensive immigration policies and the increasing sense of insecurity experienced by both the immigrants and the host communities. Immigrants face significant barriers to integration associated with their sometimes-precarious legal status and their experience of hostility and discrimination. Accordingly, urban planners and designers have a significant role to play in addressing the needs of immigrants and local residents alike. Through the design of spaces, we can promote, sustain, or undermine the requirements of diverse and multicultural cities. What follows explores whether the design of the built environment can play a role in the daily lives of immigrants by providing spaces that support integration and help cities thrive. ${ }^{2}$

\section{Immigration and the city}

Diversity represents a vital asset that opens up new possibilities, better solutions, and innovations.

Jane Jacobs ${ }^{3}$

The relatively permanent movement of people across national and international boundaries is referred to as immigration. International immigrants are further classified as legal immigrants (those who moved with the permission of the receiver nation), illegal immigrants (those who moved without permission), and refugees (those crossing an international boundary to escape persecution). ${ }^{4}$ Jay Weinstein and Vijayan Pillai, in their book Demography: The Science of Population (200I), denote another classification: forced immigrants, those who move against their will (slaves or victims of natural disaster or civil war). ${ }^{5}$ Other people leave their countries of birth in search of new lives abroad. This migratory phenomenon is called the Push-Pull factor, in which something bad about where someone lives pushes them away from where they currently live. When immigrating, people often believe that the country they are moving to will offer plenty of new opportunities, including more and better-paying jobs and improved living conditions and educational opportunities. Yet, whatever the motivation, crossing borders always involves challenges in the new country: meeting administrative requirements and

\footnotetext{
' African migration from Europe to China. VPRO documentary. 2013. YouTube. Available From: https://www.youtube.com/watch?v=fsnYIEUbO8M. Accessed February 6, 2018

${ }^{2}$ Brian, T. and Talen, E. 2017. Urban Design in a New Age of Immigration. Chicago: University of Chicago.

${ }^{3}$ Jacobs, J. (196I). The Death and Life of Great American Cities. New York: Random House.

${ }^{4}$ Migration - types of migration, 2018. Net Industries and its Licensors. Available from:

.http://family.jrank.org/pages/I I69/Migration-Types-Migration.html. Accessed November 30, 2017

${ }^{5}$ Weinstein, J. and Pillai, V.K. (2016). Demography-The Science of Population. 2nd Edition .Rowman and Littlefield, Lanham.
} 
expenses, difficulties in obtaining employment and accessing state services, learning a new language and new customs. ${ }^{6}$

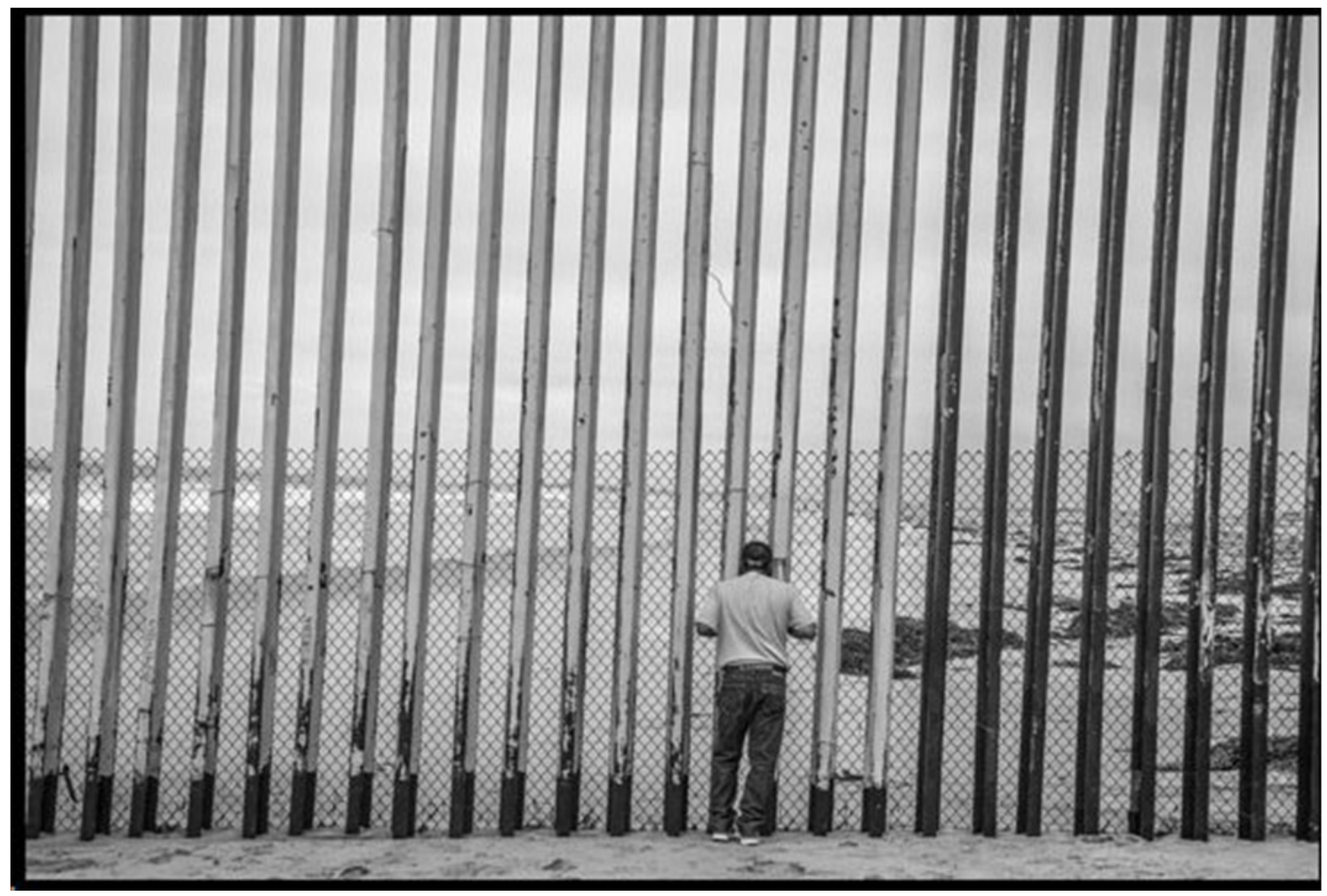

Figure I: A Tide of Return by Alex Majoli.

The greatest Western misunderstanding about immigration is that the newcomers are "other people," that "we are not all immigrants." In fact, as former World Bank administrator lan Goldin suggests, the whole world - or, at least, the "the greatest civilizations" - established themselves as a result of immigration. Ironically, while the issue of immigration - both legal and illegal - garners considerable domestic press coverage, the United States is actually experiencing a lower rate of immigration now than at any time in history. ${ }^{8}$ Furthermore, most countries in the West have currently greater control over who crosses their national borders than we did a hundred years ago, when passports barely existed. ${ }^{9}$ The Western world has become exclusive, almost a fortress, living under the illusion that one country can be a "community" without strangers. It appears that the West today is inhabited by a strong desire for apartheid, separateness. Our world is more divided then ever and the militarization of boundaries, where our borders become

\footnotetext{
${ }^{6}$ History if human migration, 2018. Wikipedia, the free encyclopedia. Available from: fhttps://en.wikipedia.org/wiki/history_of_human_migration. Accessed November 30, 2017

${ }^{7}$ African migration from Europe to China. VPRO documentary. 2013. YouTube. Available from: https://www.youtube.com/watch?v=fsnYIEUbO8M. Accessed February 6, 2018

${ }^{8}$ African migration from Europe to China. VPRO documentary. 2013. YouTube. Available from: https://www.youtube.com/watch?v=fsnYIEUbO8M. Accessed February 6, 2018

${ }^{9}$ African migration from Europe to China. VPRO documentary. 2013. YouTube. Available from: https://www.youtube.com/watch?v=fsnYIEUbO8M. Accessed February 6, 2018
} 
war zones against foreigners, contradicts all the democratic ideas upon which the Western world claims to be founded. ${ }^{10}$

\section{Identifying urban "in-betweeness"}

In spite of the resistance to immigration, the world is becoming more mixed and diverse. Due to a dramatic decline in the working age population over the next 35 years, it is anticipated that immigration will sustain current population growth and drive world economic development. "

As philosopher Achille Mbembe affirms, the stage has been set in which we have, on the one hand, the West which, due to its conservative approach to immigration, is a dormant, complacent and nostalgic society worried about where it used to be and not really knowing where it wants to go. ${ }^{12}$ On the other hand, there are dynamic regions with emergent societies, like China, Brazil, India, and Africa, where people are in motion and tolerate immigrants within their midst. In an interview with VPRO in 2013, Professor Mbembe goes on to say that the West needs to understand that the world we live in now is a totally different one and that the future sustainability of our economies more and more won't be solely decided at this end of the planet. ${ }^{13}$ At the same time, experiences of discrimination toward immigrants are increasing worldwide. Socially and economically, discrimination is tied to negative narratives fueling fear of stolen jobs, radical ideologies, crime, and poverty. Discrimination against new immigrant groups may be a "natural aspect of our psychology". According to Steven Neuberg, a professor of psychology at Arizona State University, human development made us highly dependent on people in our own groups. ${ }^{14}$ Therefore, we tend to believe that people who are foreign to us are more likely to pose certain kinds of threats, such as taking our resources, violating our norms and values, taking more than their fair share, and the like. These perceptions are false narratives that chip away at the spirit of community by limiting a welcoming attitude and increasing suspicion. Resistance toward immigrant communities becomes, at times, irrational and uncontrollable, discouraging migrants from moving to places with more economic and educational opportunities.

Literature on transnationality highlights the ambivalent nature of immigrant lives "inbetween" their country of origin and the host country. The "in-betweenness" experienced by immigrants refers primarily to their cultural/social existence. ${ }^{15}$ They live in one country while being linked to the cultures and traditions of their country of origin and, sometimes, these may not even be compatible. The ways in which one negotiates

\footnotetext{
${ }^{10}$ African migration from Europe to China. VPRO documentary. 2013. YouTube. Available from: https://www.youtube.com/watch?v=fsnY IEUbO8M. Accessed February 6, 2018

"African migration from Europe to China. VPRO documentary. 2013. YouTube. Available from: https://www.youtube.com/watch?v=fsnYIEUbO8M. Accessed February 6, 2018

${ }^{12}$ African migration from Europe to China. VPRO documentary. 2013. YouTube. Available from: https://www.youtube.com/watch?v=fsnYIEUbO8M. Accessed February 6, 2018.

${ }^{13}$ African migration from Europe to China. VPRO documentary. 2013. YouTube. Available from: https://www.youtube.com/watch?v=fsnYIEUbO8M. Accessed February 6, 2018.

${ }^{14}$ Cottrell, C.A. and Neuberg, S.L. (2004). Different Emotional Reactions to Different Groups: A Sociofunctional Threat-Based Approach to "Prejudice", Arizona State University.

${ }^{15}$ Trikalinou, L. (2018). Making Visible: The inhabitation of urban public space by irregular immigrants.

Department of Sociology Goldsmiths University of London. Available from:

https://research.gold.ac.uk/II638/I/SOC_thesis_TrikalinouL_20I5.pdf. Accessed March I3, 2018.
} 
with the new culture and manages to maintain the traditions of one's country of origin illustrates the concept of "in-betweenness." The transferability, if any, of cultural capital and its use in the forms of cultural practices reflects and informs the public space. It is here that we get the opportunity to explore the interrelationships between immigrant groups (globals) and their occupation and inhabitation of the local urban public space. ${ }^{16}$ This "in-between" space is almost always unfashionable, dangerous, undesirable, geographically unsuitable, and has poor infrastructure. It is located on the outskirts of the metropolis, alienated and low in density, a place where immigrants cannot express their best due to the lack of commercial spaces and access to public transportation. Yet, this space remains the only interface between their country of origin and the host city, and it serves as the place where people start to speculate about their future as individuals, as families and as whole urban communities.

The continuing connection to their country of origin is partly what creates the ambivalent, in-between position of urban immigrants. They belong to an ethnic community that acts as both a safety net and as the main means of socialization and support. At the same time, they are operating at the margins of a structured society, which creates the need to find a balance between the old and the new. Ultimately, one must be able to function in two often completely different, realities, and adjust to two parallel ways of life that need to be experienced as a single, coherent one. When trying to understand the immigrants' position, we must have the concept of the in-between space at the focus of our attention. ${ }^{17}$

In these spaces, global and local ideas contribute to a learning process based on acceptance, respect, and integration. Three factors prevent the in-between space from succeeding:

I. Physical barriers, caused by long distances between city centers, limited public transportation, residential buildings lacking suitable commercial spaces.

2. Institutional barriers, caused by regulations, which may be obsolete. Strict rules on hygiene and education, for instance, make it impossible for immigrants to open their own businesses.

3. Citizenship barriers, caused by complicated and possible unfeasible paths to citizenship. these barriers discourage investment by immigrants with little chance of successful integration.

Addressing these barriers require both design-based and policy-based solutions. To do so, XCOOP Rotterdam and the Centros Urbanos Javeriana, Bogotà (XCOOP+UC) have studied ways to accommodate the foreigners within the traditional urban grid by proposing a "hypothetical sustainable multi-cultural city," conceived to promote the robust inclusion of immigrants. Through a vision for the "in-between" spaces, these designers' proposals improve integration among immigrants and the communities in which they settle.

\footnotetext{
${ }^{16}$ Trikalinou, L. (2018). Making Visible: The inhabitation of urban public space by irregular immigrants. Department of Sociology Goldsmiths University of London. Available from: https://research.gold.ac.uk/II638/I/SOC_thesis_TrikalinouL_20I5.pdf. Accessed March I3, 2018. 17 Trikalinou, L. (2018). Making Visible: The inhabitation of urban public space by irregular immigrants. Department of Sociology Goldsmiths University of London. Available from: https://research.gold.ac.uk/II638/I/SOC_thesis_TrikalinouL_20I5.pdf. Accessed March I3, 2018.
} 


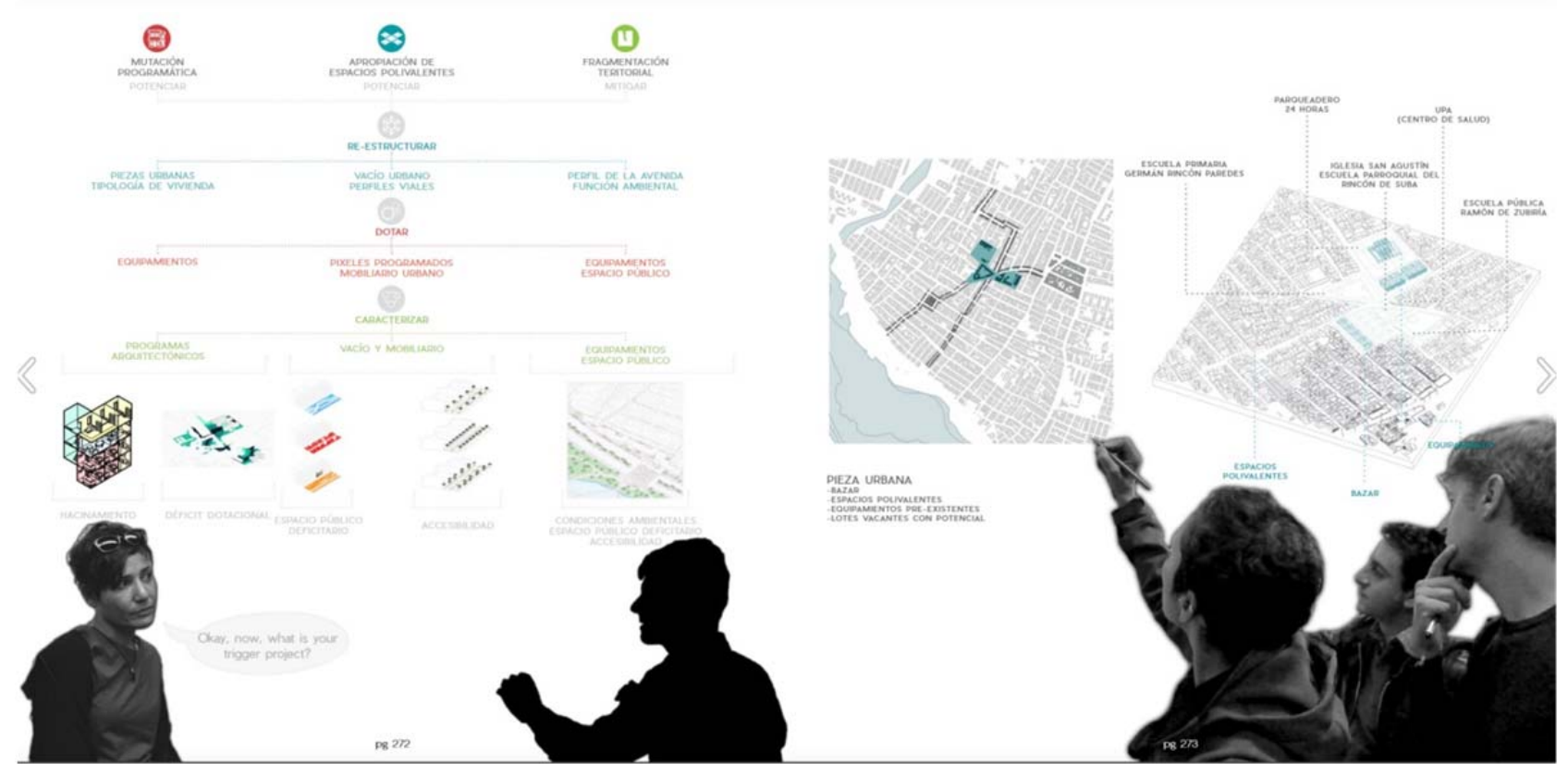

Figure 2: Urban Centers A + U Lab

The in-between space first incubates immigrant success. "[It is here] that serious and sustained investments from governments and agencies are most likely to create lasting and incorruptible benefit." ${ }^{18}$ It is here, too, where the transition from "outsider" occurs, where the next middle class is forged, and where the next generation's dreams, movements, and governments are created. Accordingly, among the proposals by $\mathrm{XCOOP}+\mathrm{UC}$ are the following:

- building public spaces designed for positive encounters among different groups;

- identifying and implementing new architectural typologies;

- improved methods of participatory design.

$\mathrm{XCOOP}+\mathrm{UC}$ plan to achieve these and other objectives by collaborating with native and foreign communities, professionals such as urban planners and social behaviorists, and colleges and universities.

\section{Challenging the division between "inside" and "outside"}

$X C O O P+U C$ 's hypothetical sustainable multi-cultural city is equipped with tools that encourage growth and support the possibility for everyone to develop and live dignified lives. Moreover, it is fundamental to allow immigrants to shape the space around them and fill the economic gap when opportunities arise. The more we can bridge between local and global communities, the more neighborhoods will continue to be revitalized. The key is to focus on quality of life for both the people who live in the city already and people who are interested in moving there. In order to make the city a welcoming place, governance needs to plan for inclusiveness, open the city to the outer world, sponsor

\footnotetext{
${ }^{18}$ Saunders, D. (2012). Arrival City: How the Largest Migration in History Is Reshaping Our World. New York: Vintage Books.
} 
growth and revitalization, maintain parks and public places, provide strong schools, and create a safe and welcoming downtown that is pedestrian-friendly and full of services. When newcomers look for places to live, they value safety, political stability, an affordable lifestyle, economic opportunity, family-friendliness, healthcare, culture, recreation, public transportation, immigrant-friendly policies, and diversity. Immigrant parents place great importance on high-quality and affordable education for their children. Good education provides future opportunities to children that the parents might not otherwise have access to. ${ }^{19}$ Without these fundamental assets, who would want to live there? Doug Saunders author of Arrival Cities, says that arrival cities are "where the new creative and commercial class will be born, or where the next wave of tension and violence will erupt." The difference, he cautions, "depends on how we approach these districts both organizationally and politically, and, crucially, in terms of physical structures and built form." It is important to keep the locals in and welcome globals from the outside to participate to the growth and redevelopment of cities.

According to the German sociologist and philosopher Georg Simmel, "Spatial relations are not only determining conditions of relationships among human beings, but are also symbolic of those relations," (197I: 143). ${ }^{20}$ Simmel continues by clarifying that "The stranger will thus not be considered here in the usual sense of term, as a wanderer who comes today and goes tomorrow, but rather as the man who comes today and stays tomorrow." This realization that the place in-between actually translates into the public space is fundamental for the team (XCOOP+UC) that starts looking at the design of a sustainable multi-cultural city as an open public space rather than a neighborhood within a neighborhood (Saunders' Arrival City). The new city is an open source environment where people meet, interact and exchange of ideas.

Public space can be seen as the "stage upon which the drama of communal life unfolds" (Carr et al., 1992: 3). Public space is the juncture of the different elements that comprise society. It is the physical place where the manifestation of the political meets individual habitation and it may shed light on questions about democracy and participation. ${ }^{21}$ Projects like BIG Superkilen in Copenhagen are of major importance to the immigrant population. A mile-long urban park wedged into one of the most ethnically diverse and socially challenged neighborhoods in Denmark, the Superkilen is a giant collection of found objects from the 60 different nationalities of the people inhabiting the area surrounding it. ${ }^{22}$ The objective was to upgrade a neighborhood to a high standard of urban redevelopment that celebrated diversity and would be likely to inspire other cities.

It is fundamental for immigrants to feel part of the design project and finally, to design the spaces they will inhabit. Ultimately, what we're looking at is "how to create healthy, high performance communities, and how do we take advantage of all the systems related to how people live and work...to create places that are much more livable and healthy." The

\footnotetext{
${ }^{19}$ Canadian Immigration \& Citizenship Lawyer 2018.

${ }^{20}$ Simmel, G. (20I I). On Individuality and Social Forms, University of Chicago Press.

${ }^{21}$ Trikalinou, L. (2018). Making Visible: The inhabitation of urban public space by irregular immigrants.

Department of Sociology Goldsmiths University of London. Available from: https://research.gold.ac.uk/II638/I/SOC_thesis_TrikalinouL_20I5.pdf. Accessed March I3, 2018

${ }^{22}$ ArchiDaily (20I2). Superkilen / Topotek I + BIG Architects + Superflex. ArchiDaily. Available from: https://www.archdaily.com/286223/superkilen-topotek-I-big-architects-superflex. Accessed November I6, 2017.
} 
goal is a community that collectively and efficiently uses its resources to facilitate growth and inclusion (Zanghi, 2016) ${ }^{23}$.

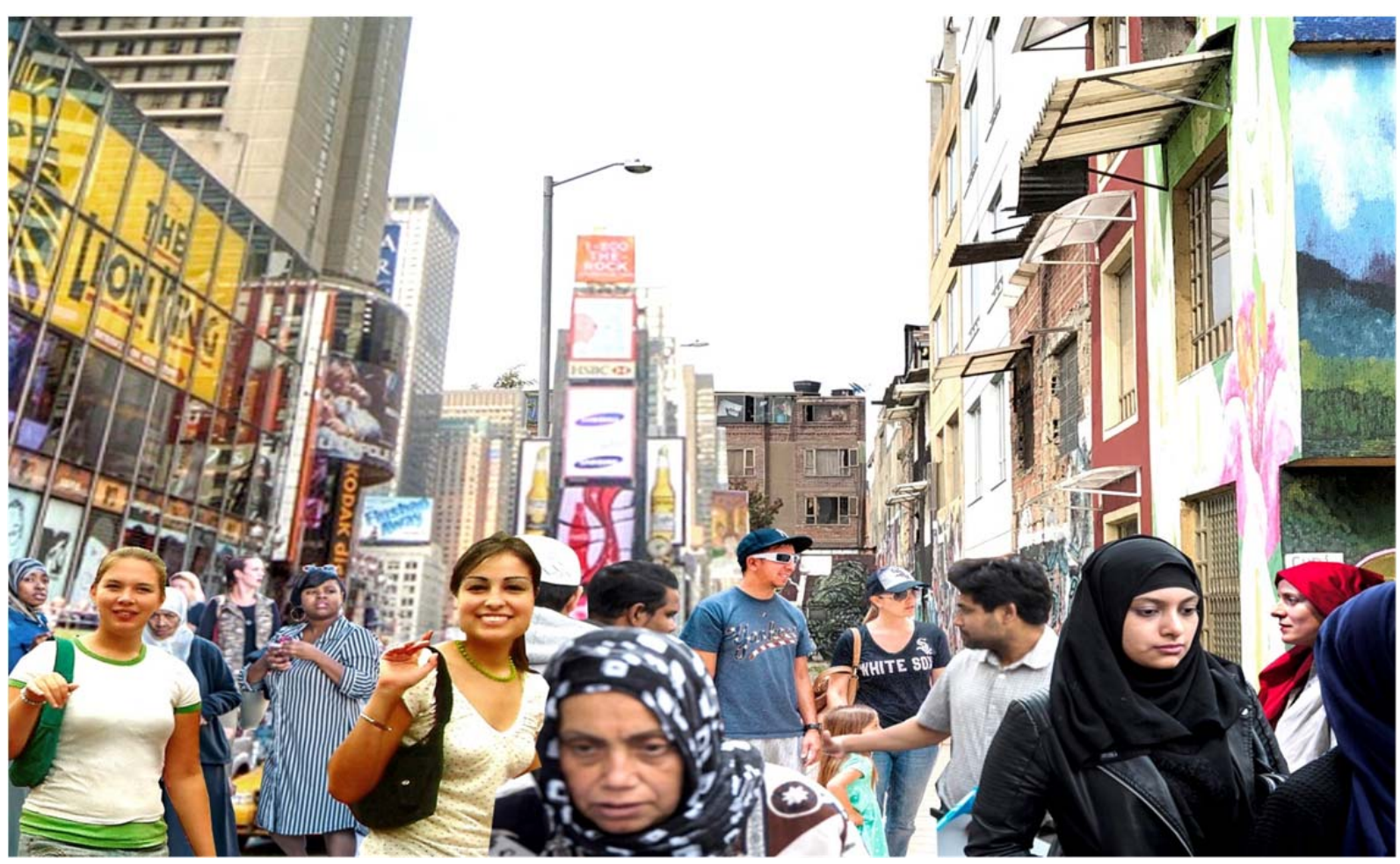

Figure 3: Collage by XCOOP

Today, public programs like Edible Alphabet at the Free Library of Philadelphia use cooking classes to teach new skills and celebrate heritage. These programs are increasingly taking the approach of meeting new immigrants halfway. The system develops around an attitude that works by cultivating the students' pre-existing expertise while simultaneously transmitting skills-like the English language- that may be helpful for adjusting to life in the welcoming country.

The International Rescue Committee's New Roots program takes a similar approach. Through a network of community farms across the U.S., New Roots offers work and training to recently arrived refugees. Urban Omnibus writes that the New Roots farm in the Bronx provides "a locale for English as a Second Language classes based on bonds beyond language forged through labor and food." The farm has also benefited the local Bronx community.

By remaining flexible and open, it's possible to strike a balance between teaching new skills and respecting people's culture. Quoting a former student, Dr. Melva Burke Leichter says: "We have to find a situation where the need to know meets the need to tell" (Anzilotti, 2016) ${ }^{24}$.

\footnotetext{
${ }^{23}$ Zanghi, A. (2016)The Importance of 'Arrival Cities'. CITYLAB.

${ }^{24}$ Anzilotti, E. (2016). How Community Centers Evolved to Help Immigrants Adjust to Life in America. CITYLAB. Available from: https://www.citylab.com/life/2016/02/community-centers-immigrants-america/4638I8/.

Accessed October 5, 2017.
} 
In the U.S., churches have a long history of devoting resources to caring for marginalized communities. Parishes around the country run soup kitchens, homeless shelters, and refugee resettlement programs. Pyong Gap Min, a professor at Queens College and CUNY's Graduate School, believes that the most powerful function a church serves is ethnic retention - a place for the next generation to learn cultural touchstones and mother tongues. These churches also give new immigrants a course in America I0I by teaching everything from how to apply for a social security card to how insurance works, (Mathew, 2017). ${ }^{25}$

Programs providing such "survival" services to newcomers can greatly inform the designer. It becomes clear that when exploring spaces for immigrants and their communities, parameters such as information exchange and security should be addressed by the design group.

\section{Designing cities where everyone can thrive}

In times of economic uncertainty and rapid demographic change, how can urban policymakers ensure and maintain equity among all citizens? What are the social and political processes that shape the responses of residents and facilitate the incorporation of foreign-born residents into local economic, social, and political life? ${ }^{26}$

Cities organize and regulate many of the activities of daily life that are crucial to the social and economic inclusion of residents. Cities can encourage two-way integration between immigrants and receiving communities revolving around opportunities for positive access of public spaces and goods. ${ }^{27}$ Within this dynamic and culturally smart urban environment, immigrants play a key role. It is a myth that immigrants take more than they give back to society. On average, immigrants (both skilled and unskilled) contribute much more than they take. ${ }^{28}$ Referring to a study done by the Center for American Entrepreneurship, Richard Florida points out that cities with high immigrant diversity are better off economically in the short, medium, and long term. ${ }^{29}$ The study describes the role that immigrants have played in creating America's largest and best-performing companies. The study points out that 43 percent of today's Fortune 500 had a first- or second-generation immigrant among their founders. Nearly a fifth (I8.4 percent) of these companies were founded by first-generation immigrants, and another quarter ( 24.8 percent) were founded by their children. All together this accounted for $\$ 5.3$ trillion in global revenue in 2016 and the employment of more than 12 million workers worldwide. ${ }^{30}$ Immigrants of all skill

\footnotetext{
${ }^{25}$ Mathew, T. (2017). How Houses of Worship Help Immigrants Adjust to America. CITYLAB. Available from: https://www.citylab.com/life/20 I 7/08/how-houses-of-worship-are-helping-immigrants-adapt-toamerica/535992/. Accessed September 18, 2017-

${ }^{26}$ Steil, J. (2016). Cities and Immigration. MIT Urban Planning.

${ }^{27}$ Ray, B. 2003. The Role of Cities in Immigrant Integration. Migration Policy Institute.

${ }^{28}$ Florida, R. (2017). Without Immigrants, the Fortune 500 Would Be the Fortune 284. CITYLAB. Available from: https://www.citylab.com/equity/2017/I2/without-immigrants-the-fortune-500-would-be-the-fortune284/54742 I/. Accessed September 25, 2017.

${ }^{29}$ Florida, R. (2017). Without Immigrants, the Fortune 500 Would Be the Fortune 284. CITYLAB. Available from: https://www.citylab.com/equity/20I7/I2/without-immigrants-the-fortune-500-would-be-the-fortune284/54742I/.Accessed September 25, 2017.

${ }^{30}$ Florida, R. (2017). Without Immigrants, the Fortune 500 Would Be the Fortune 284. CITYLAB. Available from: https://www.citylab.com/equity/20I7/I2/without-immigrants-the-fortune-500-would-be-the-fortune284/54742I/. Accessed September 25, 2017.
} 
levels, therefore, are not only creating and sustaining big companies, they are building thriving urban economies. Ian Goldin's interview with VPRO in 20I3 reports that we see this most acutely in Silicon Valley, where half of the start-ups (all the greatest iconic firms we can think of, including Google, Yahoo, and Apple), were founded by very recent immigrants. ${ }^{31}$

At a time when some countries are facing a dramatic decline in the size of the working age population, some cities are actively trying to lure immigrants as a strategy for economic and population growth. ${ }^{32}$ In Baltimore, Maryland, Mayor Stephanie RawlingsBlake said that she was counting on immigrants to help Baltimore gain 10,000 families within a decade. In Pittsburgh, Pennsylvania, immigrants have helped boost housing markets in otherwise neglected neighbourhoods, fostering new opportunities for affordable development. ${ }^{33}$ Welcoming immigrants is a logical tactic for cities trying to repopulate their neighbourhoods. Immigration must be encouraged, therefore, to contribute towards the shaping of urban space. ${ }^{34}$ Accordingly, it is now the designer's challenge to plan for sustainable cities by including the multi-cultural aspect in the new urban landscape. Key for doing so is to understand, rethink, and challenge implicit divisions between "inside" and "outside."

\section{Conclusion: moving beyond "welcoming"}

Multi-culturalism is a fact, and we are responsible for planning sustainable cities that are open and accessible to all. What will likely be remembered about this century, more than anything except perhaps changes to the climate, is the shift of populations from the South to the West, from agricultural life to cities.

Western nations that in the past have had relatively homogeneous populations are experiencing an influx of immigrants from the South, (Fuchs, L. H., 1990) ${ }^{35}$.

Immigration will continue: we cannot stop it because there are always powerful forces leading people to move from place to place in search of better lives. People living in the West cannot develop and move forward alone; we need immigrants and we need to come up with a strategy that allows us to grow, together. We need to start looking at the global citizen as one who shares a common and collective intention to develop and embrace a new direction to take.

In his book, Arrival Cities, Doug Saunders makes clear that the cities and nations that see the opportunity offered by immigrants stand to gain the most. By providing citizenship, a chance to own property, education, public transportation, and safety, such cities and host nations succeed in integrating their new arrivals, ultimately benefiting as the immigrant

\footnotetext{
${ }^{31}$ Florida, R. (2017). Without Immigrants, the Fortune 500 Would Be the Fortune 284. CITYLAB. Available from: https://www.citylab.com/equity/20I7/I2/without-immigrants-the-fortune-500-would-be-the-fortune284/54742 I/. Accessed September 25, 2017.

${ }^{32}$ Badger, E. (20I3). Why Cities Should Be Leading the Push for Immigration Reform. CITYLAB. Available from: https://www.citylab.com/equity/2013/06/why-cities-should-be-leading-push-immigration-reform/5992/. Accessed November 27, 2017.

${ }^{33}$ Wenger, Y. (2016). Mayor: Baltimore is a 'welcoming city' for immigrants and refugees. The Baltimore Sun.

${ }^{34}$ Cities of Migration. Beyond welcoming. TouTube 2017. Available from:

https://www.youtube.com/watch?v=S6SodqNcrwk and https://www.youtube.com/watch?v=yUdHJdHDH7Q. Accessed November 30, 2017.

${ }^{35}$ Fuchs, L.H. (1990). The American Kaleidoscope: Race, Ethnicity and the Civic Culture. Wesleyan University Press.
} 
class evolves into a middle class. The "in-between" places are not a static condition but a point of interchange, a place where some of the most important and surprising changes of the 2 I st century are taking place.

For urban designers, the key question raised by immigration is how to acknowledge, respect, and accommodate diversity through the built environment. As urban designers, our responsibility is to provide citizens with the opportunity for positive encounters among different groups in public spaces, equal accesses to public services and goods, implementation of new typologies, and improved methods of participatory design. We can achieve this only if all interested parties are involved in the discussion about experiences, knowledge and funding.

Spatially speaking, the influx of immigrants helps blighted neighborhoods come back to life. In Baltimore, the mayor's office is offering immigrant-friendly services such as translation, interpretation and document preparation to attract immigrants to the city. Baltimore was built for 900,000 inhabitants, but as manufacturing jobs left, and crime increased, the city's population has shrunk to about 600,000 . When cities invest in dynamic transformations and the number of abandoned buildings decreases, that provides room for individual and societal growth. ${ }^{36}$

One of the most striking examples of a city embracing diversity is New York City. Projects like nARCHITECTS' Carmel Place represent an interesting example of the successful interaction between architecture and city policy. Their proposal for microapartments in downtown Manhattan as a way of providing cost-effective, single-occupancy dwellings is largely about preserving and encouraging the diversity of the city.

"It's incredibly important to keep [the cores of the cities] as diverse as possible," explains Mimi Hoang, principal of nARCHITECTS. "I think the warning signs are in Paris, where they tend to put immigrants in this kind of immigrant belt. This obviously creates feelings of ostracization and marginalization for some in society. We have our own problems in the states of course, but the reality is that if the working class is in the periphery of the city, that is creating a hotbed of resentment."

Representing a very different approach is Catalytic Action, a Lebanese non-profit organization that sees huge opportunities in the reuse of temporary structures (such as pavilions from Expos) in the urban scape to accommodate newcomers. The concept is, basically, a simple act of recycling. Catalytic Action's Executive Director Riccardo Conti says, "The project also implies that Western countries could examine where they are producing waste and think more carefully about how they could design their products to have a useful afterlife." Although one project will not change the situation of immigrants and waste in the city, it will raise awareness of the need for spaces for immigrants in the city. ${ }^{37}$

XCOOP+UC's sustainable city creates spaces that would be points of interchange, in which people could thrive as individuals and families, and in healthy communities. It is here that the most important and surprising changes take place.

\footnotetext{
${ }^{36}$ Blanco, O. (20I5). Immigrants: These cities want you! @CNNMoney. Available from: http://money.cnn.com/2015/I2/2I/news/economy/immigrant-cities/index.html. Accessed November 7, 2017. ${ }^{37}$ Stott, R. (2016). How Migration Will Define the Future of Urbanism and Architecture. ArchDaily. Available from: https://www.archdaily.com/7908I8/how-migration-will-define-the-future-of-urbanism-andarchitecture. Accessed December 15, 2017.
} 
The global community is at the forefront of a major trend that will determine the economic and political development of the first half of the 2 I st century: the rate of immigration that flows from low wage countries is moving forward and if the West does not take advantage of this opportunity, it will have disastrous consequences for its economy, and thus for the future of its citizens.

Globalization is where we are and the whole question of immigration allows designers to rethink what cities should look like in the future. 